\title{
\begin{tabular}{lllll} 
Motrivivência & Ano XX, & No 31, P. 319-332 & Dez./2008 \\
\hline
\end{tabular}
}

\section{Fazer Educação Física: uma questão de engajamento ético do educador}

\author{
MAKE PHYSICAL EDUCATION: a matter \\ of ethical commitment of the educator
}

\section{Andrea Silvânia de Almeida' \\ Bianca Bissoli Lucas²}

\begin{abstract}
Resumo Abstract
Esse estudo foi construído a partir This study was constructed from a de uma análise reflexiva acerca do caminho que a educação física deve percorrer, enquanto estatuto epistêmico, para pensar/ articular sua intervenção pedagógica na instituição escola enquanto área de conhecimento que se articula ao processo educacional. Teve como objetivo apresentar uma reflexão acerca de uma formação pela mudança paradigmática para a constituição autônoma e reflective analysis about the way that physical education should go, while epistemic status, to think / articulate their pedagogical intervention in the school institution as a field of knowledge which is linked to the educational process. Aimed to provide a reflection on the formation of a paradigm shift for the constitution as autonomous and emancipated professional EF. It stamp literature, using thematic analysis and interpre-
\end{abstract}

Graduada em Educação Física pela Universidade Tiradentes/UNIT. Especialista em Metodologia do Ensino e Educação Física para a Educação Básica, ambas pela Universidade Federal de Sergipe/ UFS. Integrante do Grupo de Estudos e Pesquisas em História da Educação da Universidade Federal de Sergipe/UFS e, do Grupo de Estudos Pedagógicos em Educação Física da UNIT.

2 Graduada em Educação Física pela Universidade Federal do Espírito Santo/UFES. Mestre em Educação Física pela Universidade Gama Filho/UGF - Rio de Janeiro. Professora do IF-BA campus Santo Amaro ( o IF é o antigo CEFET). Coordenadora do Grupo de Estudos Pedagógicos em Educação Física/GEPEF. 
emancipatória enquanto profissional da EF. É de cunho bibliográfico, fazendo uso da análise temática, interpretativa e acrescida de reminiscência de uma graduada.

As colocações, por si mesma, elas já estão implicadas de uma introsubjetividade, ao mesmo tempo, que marcas simbólicas pelo confronto com outras, logo a troca de intersubjetividade e, o risco de não ser entendida. Porém, o convite de incomodar-se está feito.

Palavras-chave: Educação Física, Intervenção Pedagógica, Abordagem.

Conhecimento é a ferramenta interpretativa da vida; Ser professor é estabelecer o exercício de ver a vida em movimento. ${ }^{3}$

(José Américo Santos Menezes)

\section{Preâmbulo}

A epígrafe supracitada não deve ser tomada como meramente ilustrativa. Mas como síntese preliminar as considerações que se tecerá ao desenrolar da temática. tation, plus reminiscent of a cylinder. Placements in itself, they are already involved in a introsubjetividade at the same time, which marks the symbolic confrontation with others and thus the exchange of intersubjectivity and the risk of not being understood. However, the invitation to worry about is done.

Keywords: Physical education, Pedagogical Intervention, Boarding. tica pedagógica (BRACHT, 1999, 2003; KUNZ, 2004, 2006), cujo saber ou conhecimento específico volta-se a cultura de movimento (dança, luta, jogo, esporte e ginástica). Ou seja, um campo que por meio dessa cultura vai compor o processo de formação do sujeito, isto dado pelo trato pedagógico aos conteúdos no interior da instituição escolar.

Esse caráter dar-se-á a partir da atitude ${ }^{4}$ do mediador nesse espaço. Portanto, é mister compreender a necessidade a necessidade

3 Elucidação proferida durante a aula ministrada em 29 de maio de 2007, cujo disciplina intitula-se Epistemologia da Educação Física, pelo curso de especialização em EF na Universidade Federal de Sergipe - UFS.

4 Para melhor entendimento acerca de atitude ver FARINATTI, P. de T. V. 'Ciência' ou 'Cientificismo'? Reflexões sobre a transmissão de conhecimento nos cursos superiores de Educação Física. 
do indivíduo se entender enquanto profissional ${ }^{5}$ do campo. $\mathrm{E}$, assim prosseguir com resignificação da área perante a sociedade. É buscar responder as suas próprias inquietações para se entender no meio, uma busca de autoconhecimento ${ }^{6}$.

Autoconhecimento deve ser compreendido como uma ação consciente do professor ás demandas ou problemas sociais, por meio de sua prática (sócio-educativa) enquanto indivíduo influenciador no processo de formação do sujeito. Para tanto, o professor - antes de tudo - deve-se questionar quem sou? Entender-se no/do mundo, ou seja, "visitar os próprios fundamentos $^{7 \prime \prime}$ (valores humanos) e buscar relacioná-los as coisas externas do mundo, perfazendo um diálogo simultâneo (KUNZ, 2004).

Considerando essas premissas, o objetivo neste ensaio é apresentar uma auto-reflexão acerca de como pensar, articular a intervenção pedagógica na escola enquanto profissional da EF. Pois, é oportuno o que diz Bracht (1999, p.42), "quando nos referimos ao objeto da $E F$, pensamos num saber específico, numa tarefa pedagógica específica", num corpo de conhecimentos sistematizados produzidos, resignificados ${ }^{8}$ ao longo da história.

Assim, embora parta de uma posição individualizada, podese, pelo menos, oferecer ou indicar subsídios para inquietamentos futuros e/ou incomodar ${ }^{9}$ aos demais colegas que constituem o corpo/recurso humano da área, os sujeitos propulsores do campo - os profissionais.

Contudo, o estudo se justifica por perceber a aprendizagem, antes de qualquer coisa, como mudança de comportamento. Dessa forma, nada valerá um discurso "vazio" de pensar a ação pedagógica se não a coloca, não se encontra para

5 Entende-se profissional como sinônimo de professor neste texto, aqui não se coloca, para responder a essa questão, as diferenças do espaço de atuação (clubes, academias, eventos, etc), as subdivisões do campo acadêmico.

6 Para Kunz (2004, p.15), "Não se trata de formar pessoas que se conhecem melhor, apenas, mas de formar gente consciente de que jamais conhecerá tudo de si, pois isso consiste em conhecer a humanidade e o mundo $[. . .]^{\prime \prime}$.

7 Devo essa expressão a um professor, José Américo (Mequinho). Ela designa uma auto-análise de valores, ética enquanto ser humano que compõe um seio social, constituindo-se e em reunião com outros, uma sociedade.

8 Dar ao mesmo (corpo de conhecimento) um sentido próprio. Este parte de um diálogo entre si (concepções de mundo, de sujeito, entre outros) e o universo discursivo da academia.

9 Embora não seja aconselhado jargões, numa linguagem formal, vale-se aqui de um popular para melhor esclarecer ao que se refere o termo vazio. "Faça o que falo, mas não faça o que faço", ou seja, as atitudes não condizem com o que se prega, a postura esbarra-se no campo abstrato. Isso não é o mesmo que dizer: não é possível errar, até porque é preciso tentar mesmo que não seja ou não se tenha (assim deve ser) a certeza de que estar correto. 
tal prática diante da assimilação com as informações produzidas no interior da área - a academia. Acaba-se por cair ou validar o jargão "na prática a teoria é outra".

A relevância, em questão da temática, estar em haver uma pretensão ou tendência, em linhas gerais, de se querer receitas prontas e acabadas para aplicar, no cotidiano, a práxis da EF. Vale aqui as palavras de Kunz, ao apresentar o livro de Didática da Educação Física 2, "Queremos nos aproximar da realidade prática vividas pelos professores e oferecer-lhe [...] elementos concretos de atuação, que - mais uma vez - não podem ser tomados como modelos, mas exemplos a serem reavaliados, criticados e modificados." (2004, p.2, grifo meu).

\section{Como, por que, para quê ser/ agir... na EF: um fazer ético do educador}

A ciência pode classificar e nomear os órgãos de um sabiá Mas não pode medir seus encantos A ciência não pode calcular quantos cavalos de força existem
Nos encantos de um sabiá. Quem acumula muita informação perde o condão de advinhar: divinare.

Os sabiás divinam. ${ }^{10}$ (Manoel de Barros. Desejar ser. In:Livro sobre o nada)

\section{Como...?}

A vida social contemporânea é marcada, substancialmente, pela política econômica que emergiu, sobremaneira, a partir da segunda metade do século XX. Essa pode ser caracterizada pela geração compulsiva do lucro, concentração das riquezas em pequenos grupos, produção tecnológica de alto nível bem como efêmera.

Este fato, a coisificação da vida ${ }^{11}$, transforma-se em uma reflexão precisa e indispensável para estabelecer-se relações com o fazer pedagógico da EF. No entanto, torna-se um problema a partir do momento em que é preciso clarificar os significados prévios - anteriores ao contato acadêmico - que o sujeito/profissional tem. Todos somos seres que possuem "uma bagagem prévia de crenças, significados, va-

10 Epígrafe extraída do livro de Antonio Quinet. A descoberta do Inconsciente: do desejo ao sintoma. Rio de Janeiro: Jorge Zahar Ed., 2000 que faz uso do livro do Manoel de Barros. Livro sobre o nada para suas epígrafes no decorrer dos capítulos.

11 Compreende aqui como exacerbação do uso da razão instrumental enquanto foco central de articulação da existência humana. 
lores, atitudes e comportamentos" do mundo, da vida (SACRISTÁN, 2004, p.89). Todavia, o diálogo torna-se possível quando o sujeito questiona-se e compreende quanto a: de que sociedade está se falando? Que realidade sociopolíticoculturaleconômica constitui esse meio e quais suas implicações nas relações humanas? Que tipo de homem projeta essa realidade? Qual o indivíduo que pode ser pensado/ articulado para uma possível nova realidade? Como agir (estratégias) para intervir no processo de formação do homem? Que limites tem ou terá essa ação? Que pensamento de educação, cultura tem-se? O outro como percebo nas/para as relações humanas? Como discutir, na comunidade escolar, ou mais restrito ainda, no interior da escola essas questões? Pois assevera Camargo (2006, p. 41),

enquanto os animais nascem com o manual de sobrevivência instalado no organismo, nós, humanos, temos que aprender a buscar por algo que nos diga respeito. Fazemos isso através das nem sempre agradáveis experiências cotidianas, como também a partir das conseqüências a serem arcadas na de- corrência de cada escolha, num caminho que será eternamente incerto - porque indeterminado biologicamente.

Essas análises estão longe de serem respostas acabadas aos problemas sociais, educacionais, porém, estão intimamente interligadas a ação do profissional. "O conhecimento para aqueles que o possuem, se concretiza, antes, no processo de conhecer. Nesse processo conta o contexto externo e interno de quem conhece, isto é, a experiência vivida em torno do conhecimento." (Op. Cit., p.87-8). Conhecer significa estar consciente do poder do conhecimento como a produção da vida material, social e existencial da humanidade.

Por esta razão, caminhar no percurso das ciências naturais e exatas (método científico = lógicomatemático) não responde ou não permite entender os entrelaces (conduta) das relações humanas, visto que as mesmas não podem ser analisadas por partes distintas de um todo. Ao mesmo tempo, a objetivação do indivíduo não considera a condição humana $^{12}$ que se introspecta com a vida, negligencia o corpo sensível.

Farinatti, enfocando essa questão, assevera:

12 Considera condição humana, a constituição do sujeito enquanto emoção, afetividade em constante movimento com a vida. 
[...]. As abordagens excessivamente positivistas mascaram a complexidade dos fenômenos observados ao isolá-los para análise, o que é, como que, bemvindo frente à complexidade da tarefa de apreender intelectualmente os muitos significados do comportamento humano. Tudo pode ser examinados a luz dos procedimentos que envolvem a testagem de hipóteses perfeitamente identificadas. (1998, p.34, grifo do autor).

E, o fenômeno da educação é uma complexa rede de subrelações sociais (humanas), aqui se adentra a EF. Então, como se comportar nessa relação, cujo espaço não pode ser mais compreendido como área de um saber específico? Tendo um saber de base - a cultura de movimento, como estabelecer inter-relações com outros saberes?

Nesse sentido, o processo educativo passa a configurar-se não como um ensino instrumentalizado, em fins exclusivos para a preparação do indivíduo para o mundo mercadológico (do trabalho), mais também como entendimento, necessidade de uma educação estética (valores morais e éticos), o que representa uma mudança paradigmática como fundamento que ostenta, norteia a educação.

Assim, ainda que não esperando oferecer uma solução (mo- delo) para a intervenção pedagógica da EF, pretende-se, em linhas gerais, entender-se enquanto profissional da EF. Pois como coloca Lovisolo, "A ciência e a lógica podem ajudar a determinar aquilo em que não devemos acreditar, contudo são péssimas companheiras para nos dizer em quais valores devemos apostar para construir o mundo que desejamos." (1992, p.29, grifo meu).

Circunscrito nesse contexto passa a procurar visualizar a ação pedagógica a partir do próprio conhecimento interno (experiência vivida) em intersectação com o saber externo. Bem como definir uma postura possível de tratar dos conteúdos da EF no ambiente escola, o trato com o saber que vai movimentar os conteúdos é autônomo do professor.

Por que...?

Parece banal o que se segue, a princípio, mais é importante para esse processo. Conforme Lovisolo,

O educador físico, o mediador não se relaciona apenas com a articulação de áreas disciplinares. A representação e a avaliação da história, do presente e futuro de sua atividade desempenha um papel central em suas propostas. Também os 
valores que escolhe promover e realizar agem sobre as propostas. [...] (lbid., p.49-50, grifo do autor).

Como se fosse hoje (ao fechar os olhos e sentir-se na situação), o primeiro contato com membros da comunidade acadêmica (alunos e professora), em forma de círculo estavam organizados, solicitou-se a apresentação (dizia nome, idade, o porquê da escolha de EF). Prosseguiu as colocações que no tocante a explicação da opção, tinha-se sempre um vestígio de ligação do indivíduo com a esfera - prioritariamente - do esporte. Chegou-se a vez, naquele instante foi um vazio ao ver-ser diante aquele grupo, no entanto, coloca-se

queria ser professora, não sabia de que, mais tenho e a certeza do papel de mestre que desejo para a vida profissional. Não por ter tido contato com práticas esportivas, nem academia, nem lutas, nem dança e a EF vivenciada era um horror, fazia sempre corrida ao redor do espaço, pé-de-chinelo, abdominais, borboleta, flexões e o queimado para fechar o ciclo.

Todos riram. Bem, não se tinha os pré-requisitos do imaginário que os colegas acreditavam - por "falsa consciência" ou "consciência coisificada" como diz Adorno, serem indispensáveis para enquadrarse num curso de EF.

Vivida essa situação, tem um objetivo claro, buscava o papel de educar e este exige, além das competências objetivas, a habilidade de humanizar. Percebe-se o quanto estereotipa a formação, como se mercadoriza a educação, objetiva (tecnifica-se) os conteúdos, nega as diferenças/singularidades, uniformiza os indivíduos, busca homogenizar as relações humanas. Estava explícito o simbolismo de instrutor/técnico (em especificidades) da EF. Lembra Lovisolo,

A educação dos corpos, a Educação Física, emerge no bojo das atividades de intervenção dos especialistas. Sua institucionalização resulta da demanda de programas de atividades corporais [...], o corpo deve ser trabalho para ser um bom receptáculo para uma mente que, ao mesmo tempo, o considera um instrumento, um meio de realização. [...] (Ibid., p.46-7).

Pode-se inferir que não se entendia o campo enquanto prática pedagógica, professores de EF. Arriscaria a dizer, são poucos ainda os que compreendem a EF. Aqui também se coloca, contudo 
em contínua e infinita tentativa busca de entendê-la. É óbvio que mudar o comportamento, implica em tomar decisões e estas não mais podem ser de fora para dentro, ou seja, não Ihe são dados, as possibilidades e oportunidades estas sim. Toda e qualquer mudança parte de si mesmo. "Sem este trabalho de foro íntimo, toda tentativa de reflexão conjunta, toda discussão sobre currículo, corre o risco de conduzir ora à conformidade, ora à contestação sistemática." (FARINATTI, 1998, p.36).

A ação da EF esteve e ainda, embora não mais exclusiva, estar sob a influência ou norte de base da ciência positivista, que ler a realidade e no caso da $\mathrm{EF}$, o corpo e o movimento pelo fundamento da razão instrumental, em virtude de explicar ou controlar a realidade social, o comportamento humano, pelas leis universais tidas como invariáveis (BRACHT, 1999, p. 28-9). O ensinar estar pautado no conhecimento técnico desconsiderando outras dimensões - estética, cultural, social, "permitem ver o objeto [saber] não como construção social e histórica e, sim, como elemento natural e universal" (Idem, 1999, p.44-5).

Nesse espectro, uma observação ainda faz-se necessária quanto ao ser/agir em relação ao pensamento científico:
[...]. Fica cada vez mais claro que as crenças nas quais se baseia o pensamento científico refletem apenas um conjunto de idéias, que não deve ser visto nem como único, nem como o principal. Ou entende-se isso, ou aceita-se que o resultado final da atividade intelectual, da procura de explicações ao que nos cerca, é o caos. [...] (FARINATTI, 1998, p.35, grifo do autor).

O contexto sócio-histórico hodierno está arraigado dos princípios de controle da Natureza, ao mesmo tempo, em suspiros de socorro a vida. Em outras palavras, quando a ciência parece dominar a mesma apresenta-se em crise por não explicar tudo sobre a vida. Não é tão difícil encontrar exemplos a este fato, basta perguntar a ciência pela tão sonhada cura da Aids. Anos já se passaram, o mundo recorrer a ciência - como mãe legítima ao acoIhimento, embora com seus avanços sem desmerecer os significativos resultados, não encontrou ainda uma verdade acabada, absoluta.

Um outro possível exemplo caricatural pode-se fazer aos estudos para explicar a inteligência humana, esta regida por leis universais. Logo, todos seriam idênticos, no entanto, as realidades até apresentam semelhanças (aproximações), mas nenhum padrão único de 
entender-se fidedignamente, precisamente a consciência humana.

Parece que no caso de perguntar-se sobre a EF e mais especificamente, seu fazer no universo escola, a distância a esses dois exemplos ilustrativos supracitados não é estranha. Como ensinar EF partindo do princípio das disciplinas "naturais" num espaço, demanda de diversidades e realidades distintas? Levantada esta questão, remete-se a Bracht (1999, p.34) e a Camargo (2006, p. 93-4), que são categórico - respectivamente - a esse respeito,

A ciência moderna parte do pressuposto de que as explicações da realidade estão contidas nela mesma, [...]. Existem leis internas que determinam o movimento das coisas. [...] a realidade contém reguralidades e possui uma ordem. A ciência está interessada na reguralidade, na rotina, no que é comum na realidade, para controlá-la (desvelar, desvendar a realidade, descobrir as leis que a regem).

Em suma, pode-se dizer que pensar a intervenção da EF constitui em compreender as rea- lidades (cada uma terá sua especificidade, singularidade) como humanidades construídas socialmente e históricas, portanto, a idéia de pensar uma "realidade sob medidas ${ }^{13 "}$ vai à falência enquanto ação pedagógica. Portanto,

o engajamento ético do educador diverge de qualquer tentativa que vise moldar, regrar, regulamentar ou normatizar comportamentos [...]. Apostar no sucesso de uma educação em decorrência deste ou daquele artifício prescrito - metodológico [entenda reação previsível, manipulação do agir] mais ou menos explícito não faz mais que revelar a ilusão de abster-se dos riscos impostos pela aventura pedagógica/ educativa, que muito tem a ver com o risco de estar em contato permanente com o inefável, o avesso e o inesperado, já que a docência [leia as relações humanas] é vivida no campo das trocas intersubjetivas, onde surgem imagens outras que insistem não ser idênticas àquelas do próprio educador ao mirarse no espelho...

13 Faz uma interpretação a partir de Farinatti (1998, p.35), quando se refere aos indivíduos que articulam o saber conforme os conceitos, teorias cientificistas, o qual é pensado em sua esfera imune "que se revela sempre verdade, independente das circunstâncias." "Assim, não farão parte desse conhecimento os aspectos sociais ligados à afetividade do sujeito que se move, os aspectos sociais ligados ao contexto em que se realiza o movimento e o que o influenciam, etc [...] não existe uma abordagem global que 'esgote' a realidade." (BRACHT, 1999, p.35). 
Para quê...?

A priori, é pertinente ressaltar que o campo da EF, ousa-se falar, ainda estar em constituição, quando o percebe em função da construção - própria - de uma pedagogia da $\mathrm{EF}^{14}$. Indubitalvemente, essa elaboração requer a discussão entre os profissionais que estam na escola, na academia e na pesquisa "referente à relação entre Educação e Movimento/Corpo Humano." (KUNZ, 2006, p.15).

Para Adorno a racionalidade moderna tornou-se manipuladora, cúmplice com uma dominação ideológica - volta-se especificamente para o processo educacional - tratando a educação como aquisição de conhecimentos técnicos (Idem, 2000, p. 11). E em crítica a tal, Adorno e Horkheimer (1973, p. 193) dizem que: "A ideologia contemporânea é o estado de conscientização e de nãoconscientização das massas como espírito objetivo, e não os mesquinhos produtos que imitam esse estado e o repetem, para pior, com a finalidade de assegurar a sua reprodução." ${ }^{\prime 15}$.

Adorno não hesita em expor que o maior desafio da educação esteja em enfrentar a barbárie, tão logo, ela mesma precisa de uma auto-reflexão quanto a sua função, ou melhor, ao papel que a educação está assumindo. Aqui especialmente, os esforços tentam se ater ao processo educacional institucional, cujos projetos pedagógicos, em geral, constituem-se numa ideologia dominante com auto-imposição de valores pragmáticos.

Endossando o caso de Auschwitz, o autor pretende esclarecer as deficiências que os projetos educacionais estão diante, quando esses projetos envolvem o caráter humano "as tentativas de combate à reincidência desviam-se necessariamente para o lado subjetivo." (ADORNO, 1986, p. 34). Ou seja, a educação sonega sua responsabilidade para acontecimentos do gênero transferindo exclusividade aos fatores psicológicos do indivíduo (neurose, psicose, os tidos irracionais), no entanto, suprime o princípio que a formação do homem é constituída em suas relações com o mundo. E neste sentido, "a civilização produz a anticivilização e a reforça progressivamente." (lbid., p.33).

Parece que quanto mais "civilização" se tem, aumenta-se

14 Para Kunz (2006, p. 15;18), é o consenso didático-metodológico entre os significados de "educação e formação humana" numa relação concomitante "às possibilidades empíricas da cultura de movimento."

15 Ideologia na acepção de pensamento crítico-reflexivo do homem em sociedade. 
uma tendência a sair dela, algo favorável a barbárie. Esta não estar somente no estado bruto da ação do homem, mais também na condição que se tem de humanização. Observe o que dizem Adorno e Horkheimer (1973, p.95): "Hoje em dia, os defensores da cultura levam mais em conta a instalação de recinto para conservar o patrimônio cultural do que os valores espirituais da humanidade."

Adorno, em seu texto sobre "Educação para quê?" estabelece o sentido/significado sobre a educação para sociedade, interpretando educação como elemento proporcionador de intervenção política, para cada indivíduo em sua sociedade e afirma que essa intervenção não se dá pelo que lhe é apresentado, mas pela "decisão consciente de cada pessoa em particular" sobre o mesmo. Considera que o indivíduo ao alcançar esta capacidade, o mesmo está em condições de ser emancipado em sociedade, razão da educação (ADORNO, 2000, p. 139-54).

Reportando para a EF, remete-se a Paiva (2003, p.75), em seu texto Constituição do campo da educação física no Brasil: ponderações acerca de sua especificidade e autonomia, ao ser intransigente que o princípio, ou melhor, pode ser o desafio, de base seja a autonomia do campo, uma vez que quanto maior a autonomia relativa do campo, maior a possibilidade de outro tipo de relação com o mercado que não seja necessariamente a de reprodução, já que é aqui que se obnubila o poder de constituição dos sistemas simbólicos.a autonomia pode garantir a produção de sentidos próprios e melhores condições de enfrentamento. [...]

Pelo menos a partir desta perspectiva, é possível falar de uma EF pedagógica com função social, formativa no cotidiano escolar, uma hipótese de coibir a possibilidade de o retrocesso na EF bem como um elemento corroborador a educação para se evitar um novo Auschwitz, a barbárie.

\section{Aproximações finais}

Para apreender o apresentado, é essencial esclarecer que tanto os autores recorridos quanto a responsável pelo estudo são sujeitos, ou seja, ainda que não seja certo, sobretudo para a escrita deste trabalho, há uma sutil interpretação (análise, reflexão) pessoal, individual. E, portanto, o conteúdo em questão não se coloca como acabado ou verdade absoluta.

A essa educação, e a EF integra esse projeto maior, implica em uma postura crítica de seu mundo 
presente para que a probabilidade de práticas sociais futuras seja transformadora e não recaia sob a barbárie, como as já vistas. Para tanto, é necessário o reconhecimento dos paradoxos que assoalham o projeto educacional, entre as quais subjetividade/objetividade, individualidade/coletividade, irracionalidade/ racionalidade, particularidade/universalidade. Portanto, como pode a EF responder a esses aspectos por via do cientificismo positivista? Será possível lidar com esses emblemas pelas ciências naturais? É preciso analisar essas questões a partir do estatuto epistemológico como possíveis fundamentos para o ser/agir da EF na escola.

Assim, para finalizar esta reflexão fica-se o questionamento - este é prolongamento, ainda, do período de graduação - que, considera, deve ser enfrentado pela reflexão filosófica na intervenção da EF escolar. Sendo o indivíduo um ser histórico-cultural capaz de construir ou transformar sua sociedade, a EF pode oferecer subsídios, conhecimentos, que venham a desenvolver esta capacidade? Deve ela, diante interesses particulares de um grupo, impor, edificar a história do indivíduo.

A determinação das bases teóricas para nortear o processo educativo na educação física vai estar ligada intimamente como o conhecimento será refletido ao indivíduo. A ausência de uma compreensão minuciosa dos objetivos propostos pela abordagem escolhida pode ser, em parte, responsável pela permanência da alienação do ser (condução ao estado de barbárie), bem como a falta de legitimação da educação física.

Finaliza-se estas linhas com uma citação de Bastos, extraída de "A construção da pessoa em Wallon e a constituição do sujeito em Lacan" (2003, p. 44; 117),

Mais que tudo é preciso querer, desejar, buscar novos questionamentos, não se limitar às velhas e ultrapassadas respostas, se deixar 'virar do avesso', se desalojar do lugar de 'mestre', buscar novos sentidos e implicações para suas ações, construir um novo olhar sobre si e sobre o outro, enfim, caminhar na construção de um saber singular.

E, acrescenta "[...] Enquanto se queixa dos outros e atribui a culpa a eles, não pode perceber sua própria implicação na situação em que está incluído. [...]".

\section{Referências}

ADORNO, T. W. Educação após Auschwitz. In: 
Sociologia. Tradução Gabriel Cohn. São Paulo: Ática, 1986, cap. 1, p. 33-45. (Coleção Grandes Cientistas Sociais).

- À guisa de introdução:

Adorno e a experiência formativa. In: Educação

e Emancipação. 2.ed.Tradução Wolfgang Leo Maar. Rio de Janeiro: Paz e Terra, 2000.

BASTOS, A. B. B. I. A construção da pessoa em Wallon e a constituição do sujeito em

Lacan. Petrópolis: Vozes, 2003. BRACHT, V. Epistemologia da educação física. Educação Física e Ciência: cenas de um casamento (in)feliz. ljuí: Unijuí, 1999.

CAMARGO, A. C. C. S. de.

Educar: uma questão metodológica?Proposições psicanalíticas sobre o ensinar e o aprender. Petrópolis: Vozes, 2006.

FARINATTI, P. de T. V. 'Ciência' ou 'Cientificismo'? Reflexões sobre a transmissão de conhecimento nos cursos superiores de Educação Física. Revista Brasileira de Ciências do Esporte. Número especial-20 anos de CBCE, set. 1998, p. 32-8.

HORKHEIMER, M.; ADORNO, T. W. (orgs.). Temas Básicos de Sociologia. Tradução Álvaro Cabral. São Paulo: Cultrix; Ed. da USP, 1973.
KUNZ, E. Práticas Didáticas para um "Conhecimento de Si" de Crianças e Jovens na Educação Física. In: . Didática da

Educação Física 2. $2^{\mathrm{a}}$ ed. ljuí: Unijuí, 2004, cap. 1, p. 15-52. . Pedagogia do esporte, do movimento humano ou da educação física? In: KUNZ, E.; TREBELS, A. H. Educação física crítico-emancipatória: com uma perspectiva da pedagogia alemã do esporte. Ijuí: Unijuí, 2006, cap. 1, p. 11-22.

LOVISOLO, H. Educação física como arte da mediação. Revista Contexto \& Educação. Ijuí, 7(29): 26-59, 1992.

TARDIF, M. Os professores diante do saber: esboço de uma problemática do saber docente. In: . Saberes docentes \& formação profissional. Petrópolis: Vozes, 2002, cap. 1, p. 31-55.

SACRISTÁN, J. G. Currículo e diversidade cultural. In: SILVA, T. T. da; MOREIRA, A. F. (orgs.). Territórios contestados: o currículo e os novos mapas políticos e culturais. 6. ed. Petrópolis,RJ: Vozes, 2004, cap. 4, p. 82-113.

Andrea Silvânia de Almeida andreaunit@hotmail.com (79)99565058

Av. Heráclito Rollemberg, 4554, Bl.09, Apt $^{\circ}$ 101, Orlando Dantas 49042-190Aracaju/SE 
Bianca Bissoli de Lucas

biabis@ig.com.br

(75)81292938

Av. Francisco Moreira, 741, bloco

E, Apart. 304- Luzia

49000-000

Recebido: 03/fevereiro/2010.

Aprovado: 12/abril/2010. 